\title{
Evaluación de las competencias digitales sobre seguridad de los estudiantes de Educación Básica
}

\section{Assessing the digital-safety competences of students in Basic Education}

\author{
Ana García-Valcárcel Muñoz-Repiso \\ Universidad de Salamanca. Salamanca, España \\ anagv@usal.es \\ Laurentino Salvador Blanco \\ Universidad de Cantabria. Santander, España \\ laurentino.salvador@unican.es \\ Sonia Casillas Martín \\ Universidad de SalamancaSalamanca, España \\ scasillasma@usal.es \\ Verónica Basilotta Gómez-Pablos \\ Universidad a Distancia de Madrid. Madrid, España \\ veronicamagdalena.basilotta@udima.es
}

\section{Resumen}

El objetivo del trabajo es elaborar y analizar una prueba de evaluación dirigida a estudiantes que finalizan la Educación Primaria. La prueba se ha diseñado para medir los conocimientos, capacidades y actitudes de los estudiantes en las 4 competencias del área de seguridad señaladas en el modelo DigComp (protección de los dispositivos, de los datos personales, de la salud y del medio ambiente). Para su análisis ha sido aplicada a 600 estudiantes entre 12 y 14 años. Los ítems muestran unos índices adecuados de discriminación y dificultad, así como se encuentran correlaciones significativas entre las dimensiones de conocimiento, habilidad y actitud. La fiabilidad de la prueba se ha estimado en Alfa de Cronbach=0,68. La validez se ha asegurado mediante juicio de expertos y el análisis de la estructura factorial de la prueba.

Palabras clave: educación básica, seguridad online, cibercultura, digcomp.

\begin{abstract}
The objective of this study is to develop and analyse an evaluation test aimed at students who are at the end of their Primary Education. The test is designed to measure the knowledge, abilities and attitudes of students in the 4 safety competences identified in the DigComp model (protecting devices, personal data, health and the environment). The test was administered to 600 students aged between 12 and 14 in order to analyse it. The items show some suitable discrimination and difficulty indices, and significant correlations between the dimensions of knowledge, skill and attitude were also found. Test reliability was estimated with a Cronbach's Alpha of 0.68 . Validity was ensured through experts' judgment and analysis of the test's factorial structure.
\end{abstract}

Keywords: scholarship, online security, evaluation, cyberculture, digcomp. 


\section{CONTEXTUALIZACIÓN TEÓRICA}

La sociedad de la información requiere la formación en el uso de las tecnologías digitales. Los aprendizajes referidos a esta cuestión constituyen lo que se ha dado en llamar competencia digital (Ferrari, 2013; García-Valcárcel, 2016), alfabetización digital (Area, 2012; Coll y Rodríguez-Illera, 2008), digital literacy (Bawden, 2008; Lankshear y Knobel, 2008), alfabetización o competencia mediática (Gutiérrez y Tyner, 2012; Jenkins, 2009), habilidades digitales (Van Dijk y Van Deursen, 2014), nuevos alfabetismos (Dussel, 2009; Gewerc y Montero, 2015), alfabetización informacional (Alonso, 2012; Fontdevila, 2012), etc.

Tomando como referencia el proyecto DigComp, se puede definir la competencia digital (CD) como un conjunto de conocimientos, habilidades, actitudes, estrategias y valores que son puestos en acción cuando usamos las tecnologías y los medios digitales para realizar tareas, resolver problemas, comunicarse, tratar información, colaborar, crear y compartir contenidos y crear conocimiento, de forma efectiva, eficiente, apropiada, crítica, creativa, autónoma, flexible, ética y reflexiva para el trabajo, el ocio, la participación, el aprendizaje, la socialización, el consumo y el empoderamiento (Ferrari, 2013:30).

Este proyecto distingue 5 áreas competenciales que conforman la $\mathrm{CD}$ (Información, Comunicación, Creación de Contenidos, Seguridad y Resolución de problemas) y que agrupan 21 sub-competencias, que se refieren a aprendizajes clave para la participación de los ciudadanos/as del siglo XXI.

Una buena formación en CD podría evitar muchos problemas debidos al uso excesivo e indebido de Internet y las redes sociales, lo cual puede interferir en la vida académica y social de los estudiantes (García-Umaña, 2017; García-Umaña y Tirado-Morueta, 2018), así como tener consecuencias psicológicas negativas, como el denominado FOMO ("Fear Of Missing Out"), patología psicológica que se produce por el miedo a quedarse fuera del mundo tecnológico o a no seguir el ritmo que la tecnología exige (Oberst, Wegmann, Stodt, Brand y Chamarro, 2017).

En cualquier caso, no es la frecuencia de uso, sino para qué lo están utilizando y la seguridad de su uso lo que genera preocupación, pues aplicando una debida alfabetización mediática podría generar beneficios (Aguaded y Tirado, 2008; Odgerd, 2018). Diversos autores (Ilomäki, Kantosalo y Lakkala, 2011; Sekret y Kommers, 2014) han identificado dominios competenciales que amplían las habilidades personales y sociales con las tecnologías, incorporando su uso en las prácticas escolares y también el bienestar emocional, lo que nos lleva a considerar la competencia digital como clave para el bienestar. En este sentido, los hallazgos obtenidos por De Pablos-Pons, Colás-Bravo, Conde-Jiménez y Reyes-De Cózar (2017) indican que la percepción de los escolares sobre la propia competencia digital está ligada y asociada a tres variables; el uso personal y social de los recursos tecnológicos, la internalización que los sujetos hacen de las tecnologías (ligada a prácticas escolares), así como los estados emocionales asociados a estos usos.

Evaluación de las competencias digitales sobre seguridad de los estudiantes de Educación Básica, García-Valcárcel, A., Salvador, L., Casillas, S. y Basilotta, V.

Página 2 de 34 
Además, el desarrollo de la $\mathrm{CD}$ es un aspecto clave que permitirá afrontar la igualdad de oportunidades y el desarrollo económico, la participación ciudadana y la inclusión social (Sánchez, Muñoz y Paredes, 2015). Por esta razón, la competencia digital y, en concreto, las capacidades y actitudes relacionadas con la protección de los dispositivos, de los datos personales, de la salud y del medio ambiente, deben ser objeto de evaluación en los niveles educativos básicos, con el objeto de formar ciudadanos capaces de hacer un uso beneficioso y productivo de las tecnologías digitales. Este es uno de los objetivos del proyecto de investigación financiado por el Ministerio de Economía y Competitividad de España MINECO/FEDER (Ref. EDU2015-67975-C3-3-P), algunos de cuyos resultados se presentan en este artículo.

En cuanto a la evaluación de las competencias, se puede definir como "un procedimiento en el que se requiere que el estudiante complete tareas o procesos en los que se demuestre su habilidad para aplicar conocimiento y destrezas o aplicar conocimientos en situaciones simuladas similares a la vida real" (Castro, 2010:118). Si entendemos por competencia la puesta en acción de conocimientos, habilidades y actitudes, necesita ser evaluada de modo integral y no cada uno de sus elementos de manera separada (Villa y Poblete, 2011). En este sentido, Code, Clarke-Midura, Zap y Dede (2011:235) destacan que para desarrollar una evaluación efectiva de competencias se "requiere del análisis de los procesos cognitivos y de las estructuras que contribuyen al desempeño de las tareas". Se trata de pasar de una evaluación del aprendizaje a una evaluación para el aprendizaje (López Pastor, 2009). Este tipo de procesos evaluativos, pese a sus evidentes potencialidades, también plantea ciertas dificultades, especialmente vinculadas con la viabilidad y las características psicométricas de los instrumentos utilizados (Clarke y Dede, 2010). De acuerdo con De la Orden (2011), consideramos de especial relevancia que, más allá del instrumento, las competencias deben estar claramente definidas, los criterios y estándares de evaluación deben ser representativos de los contenidos y las tareas percibidas como significativas para los alumnos.

Podría establecerse una clara diferenciación entre distintos tipos de investigaciones que tienen como foco la evaluación de la competencia digital, atendiendo a las herramientas que utilizan: por un lado, los instrumentos que se centran en la autopercepción del sujeto y, por otro, los que implican la resolución de problemas. En el primer caso, los trabajos analizan la imagen que los individuos tienen de sí mismos sobre diferentes aspectos relacionados con la competencia digital, mientras que en el segundo se realizan evaluaciones propiamente dichas de ésta.

Destacan aquellos estudios de autopercepción que toman como referencia la dimensión informacional de la CD. Desde esta perspectiva el trabajo de Rodríguez, Olmos y Martínez (2012) analiza la autopercepción del alumnado universitario. También se incluye en esta línea el estudio desarrollado por Ferrés, García, Aguaded, Fernández, Figueres y Blanes (2011) que aborda el análisis de la CD en el conjunto de la ciudadanía mediante la aplicación de cuestionarios, entrevistas y grupos de discusión. Desde este mismo ámbito, destaca igualmente el test de alfabetización digital on-line (Test ADO) como indicador de la competencia mediática (Dornaleteche, Buitrago y Moreno, 2015). Se trata de una herramienta de autopercepción aplicada a la ciudadanía cuyos resultados y conclusiones

Evaluación de las competencias digitales sobre seguridad de los estudiantes de Educación Básica, García-Valcárcel, A., Salvador, L., Casillas, S. y Basilotta, V.

Página 3 de 34 
generales, muy en sintonía con el estudio de Ferrés et al. (2011) indican que el nivel de alfabetización digital on-line del ciudadano medio no es el deseado y que existe una brecha digital generacional y de género, ya que las mujeres se muestran menos empoderadas que los hombres. Por otra parte, indican que el perfil medio del usuario de internet es más social, recreativo y consumidor de contenidos existentes, que proactivo, gestor y creador de contenidos propios.

En el mismo sentido, González, Espuny, De Cid y Gisbert (2012) trabajan con una herramienta de autopercepción denominada INCOTIC para Educación Secundaria Obligatoria. Buscan poder incidir directamente en aquellos ámbitos en los que los estudiantes presenten un menor nivel de competencia. También desde la autopercepción, pero orientado a adolescentes en riesgo de exclusión social, el cuestionario desarrollado por Carrera, Vaquero y Balsells (2011) permite evaluar las dimensiones y componentes de la CD permitiendo determinar las necesidades de alfabetización digital.

En el ámbito de la Educación Primaria, los estudios realizados encuentran un nivel de competencia limitado, considerando dimensiones como actividades diarias con TIC, competencia del alumnado en TIC, uso correcto de Internet y herramientas TIC, uso colaborativo de las TIC, representación de información mediante las TIC, motivación y autonomía del alumnado (Martínez- Serrano, 2018; Villegas, Mortis, García y del Hierro, 2017) y concluyen que los alumnos utilizan las TIC más para actividades de esparcimiento que para labores escolares. Por su parte, García, Duarte y Guerra (2014) abordan la evaluación de la $\mathrm{CD}$ en la Educación Infantil mediante un cuestionario que permite establecer tres niveles de competencia: excelente, aceptable y mínimo.

Algunos estudios internacionales recientes, como el de Aesaert y Van Braak (2014), han analizado el grado en que distintos factores vinculados al alumnado de Educación Primaria, así como a las características de su aula, escuela y familia, inciden en la autoeficacia digital de los estudiantes y en la autopercepción de su competencia digital. Los resultados indican que los alumnos/as de primaria tienen una alta percepción de sí mismos en lo que respecta a sus habilidades de recuperación y tratamiento de la información digital, así como de comunicación a través de ordenadores e internet (Aesaert y Van Braak, 2014: 336). Así mismo, se encontró que los factores condicionantes de esa autopercepción digital no se situarían tanto en el nivel de aula y centro, como en las características del propio alumnado y sus familias, dependiendo de las variables experiencia y actitud ante las TIC (estudiantil y parental), así como de los estilos de aprendizaje, la inteligencia analítica y los factores motivacionales. Estos hallazgos van en la línea de otros estudios (Vekiri, 2010; Zhong, 2011) que coinciden en subrayar la relevancia de los factores e influencias familiares, socioeconómicas, socioculturales y el contexto extra-escolar como potentes predictores de la autoeficacia digital de niños/as y adolescentes. Investigaciones como las de Claro, Cabello, San Martín y Nussbaum (2015) proporcionan evidencias respecto a los profundos efectos que la situación económica, social y cultural tiene sobre las competencias digitales de los estudiantes. De hecho, sus resultados muestran que el nivel educativo de los padres y madres es el factor más relevante para explicar el rendimiento del alumnado chileno en las pruebas de evaluación nacional de la competencia digital, reflejando la existencia de una segunda

Evaluación de las competencias digitales sobre seguridad de los estudiantes de Educación Básica, García-Valcárcel, A., Salvador, L., Casillas, S. y Basilotta, V.

Página 4 de 34 
brecha digital en el campo de la educación. El impacto de la experiencia TIC en la escuela sería así indisociable al de la experiencia en el hogar, conduciendo a determinados niveles de autoeficacia digital, siempre mediada a través de experiencias positivas (Aesaert, van Braak, Van Nijlen y Vanderlinde, 2015).

Profundizando específicamente en las dimensiones de la CD relativas a la seguridad, detectamos que constituyen uno de los aspectos de mayor preocupación, de cara a orientar las políticas de protección a la infancia y la juventud. En este sentido, el proyecto Eukids online (http://www.eukidsonline.net), financiado por la Unión Europea, se focalizó en los riesgos de la conexión online, en relación a acoso, bullying, etc. (Livingstone, Haddon, Görzig y Ólafsson, 2011). Se evidencia que el 93\% de usuarios/as de 9 a 16 años de edad están en línea al menos semanalmente (un $60 \%$ todos o casi todos los días); este acceso se produce a edad cada vez más temprana y a través de dispositivos móviles en casa. El 59\% de los niños/as tienen un perfil en las redes sociales. El estudio coincide con el ofrecido por PROTEGELES, dependiente del Safer Internet Programme de la Comisión Europea (Cánovas, García de Pablo, Oliaga y Aboy, 2014) que analizó el fenómeno de la conectividad móvil entre los más pequeños, así como sus implicaciones a través de encuestas realizadas a niños/as de 11 a 14 años. De ambos estudios se desprende la necesidad de un trabajo educativo, tanto en las familias como en las instituciones educativas.

En la línea de los trabajos que evalúan el nivel de competencia digital (y no ya su autopercepción), el estudio realizado por Van Deursen y Van Dijk (2011), indagó en el nivel de habilidades para el uso de internet en la población holandesa (un grupo significativo fueron los estudiantes de primaria y secundaria) y los factores que lo determinan, entendiendo que la exclusión digital está estrechamente ligada a la exclusión social. Los hallazgos muestran la importancia de la formación y el entorno cultural del estudiante en el desarrollo de esta competencia, más que los años de uso de internet o las horas que le dedica (He y Li, 2019; Van Deursen, y Van Diepen, 2013).

Otro referente es el trabajo desarrollado desde la Educational Testing Service (ETS) a través de la herramienta de evaluación iSkills. Su objetivo es medir las habilidades de los estudiantes universitarios a la hora de investigar, organizar y comunicar la información con tecnología (Katz, 2007). Otras herramientas para evaluar la CD podrían verse en el Information Literacy Test (ILT), orientado al ámbito universitario, evalúa la CD de los sujetos a través de cuestionarios de respuesta única (Cameron, Wise y Lottridge, 2007). Esta propuesta está en la línea de otras herramientas como el Kent State University's Project SAILS, ETS's i-Critical Thinking Certification o el James Madison University's Information Literacy Test (Fain, 2011). Por su parte, Kim y Choi (2018) proponen una Escala de Ciudadanía Digital para adolescentes percibida por sus profesores (modelo SAFE) que contempla cinco factores: Identidad propia en el entorno digital, Actividad en línea (Actividad razonable y Participación social/cultural), Fluidez para las herramientas digitales y Ética para el entorno digital. En el ámbito de la Educación Secundaria se ha elaborado el cuestionario Instant DCA (Calvani, Fini, Ranieri y Picci, 2012) como una alternativa al European Computer Driving License (ECDL) más centrado en los aspectos técnicos de la competencia. Teniendo en cuenta todo lo dicho, es de resaltar que los trabajos que evalúan 
la CD constatan el peso e influencia del entorno socio-familiar, si bien se basan mayoritariamente en la autopercepción de los sujetos y son escasos los trabajos que estudian esta competencia en la educación obligatoria. Se pone de manifiesto entonces la necesidad de conocer en profundidad qué conocimientos, habilidades y actitudes poseen los jóvenes estudiantes de una forma objetiva, cuestión que ha sido abordada en el presente estudio.

\section{METODOLOGÍA}

El objetivo perseguido es construir una prueba de evaluación de las competencias digitales de los escolares en el ámbito de la seguridad, contemplando sus conocimientos, habilidades y actitudes; y analizar sus características psicométricas, incidiendo en su fiabilidad y validez. Para ello, un equipo de investigación compuesto por profesores universitarios y maestros han colaborado en el marco del proyecto de investigación. El diseño del instrumento ha tomado como referencia los modelos alternativos de evaluación, centrados en la metodología de aprendizaje basado en problemas (Mateo y Martínez, 2008). Se plantea de modo que los conocimientos y habilidades se miden a través de ítems que presentan situaciones en las que los estudiantes tienen que tomar decisiones, seleccionando una respuesta determinada, para demostrar el grado de consecución de las competencias digitales. Por otra parte, las actitudes se valoran a través de una escala tipo Likert.

Para el estudio del instrumento, se aplica a una muestra de estudiantes de centros educativos seleccionados aleatoriamente, empleando una metodología cuantitativa (prueba objetiva y escala de actitudes). El diseño del estudio es de corte descriptivo y transversal, puesto que la información se recoge en un único momento, durante el curso 2018-19.

\section{Participantes}

La muestra de estudiantes se ha seleccionado mediante un muestreo aleatorio estratificado de los centros educativos de Primaria y Secundaria de dos provincias españolas, teniendo en cuenta los criterios público/concertado y rural/urbano. Se ha conseguido la colaboración de 18 centros educativos y una muestra de 600 estudiantes entre 12 y 14 años, equilibrada en cuanto al género (49\% niños $/ 51 \%$ niñas), siendo la mayoría del último curso de Primaria ( $85 \%$ de $6^{\circ}$ de Primaria, frente al $15 \%$ de $1^{\circ}$ de Secundaria).

\section{Instrumento}

En primer lugar, se identifican los conocimientos, habilidades y actitudes que conforman las competencias de Seguridad para jóvenes de estas edades, tomando como referencia el modelo DigComp de amplia implantación en Europa (García-Valcárcel, Hernández, Mena, Iglesias, Casillas, Cabezas, González, Martín y Basilotta, 2019a). Así se elabora un modelo de 72 indicadores que será validado mediante la consulta a jueces (11 expertos de diferentes niveles educativos) que valoran la importancia, pertinencia y claridad de los mismos.

Evaluación de las competencias digitales sobre seguridad de los estudiantes de Educación Básica, García-Valcárcel, A., Salvador, L., Casillas, S. y Basilotta, V.

Página 6 de 34 
Todo ello nos conduce al diseño de una prueba inicial formada por 68 ítems, 25 de conocimientos/habilidades (tipo prueba objetiva, 4 alternativas de respuesta) y 43 ítems de actitudes (respuesta tipo Likert, 5 alternativas). Los ítems fueron sometidos a discusión por pares y valoración de expertos, realizando las modificaciones pertinentes, tanto en contenido como en redacción.

Tras un estudio piloto en el que se aplica la prueba a 75 estudiantes de $6^{\circ}$ de Primaria pertenecientes a 5 colegios, se depuran y modifican algunos ítems y la prueba definitiva queda conformada por un total de 22 ítems, 6 referidos a conocimientos, 10 sobre habilidades y 6 de actitudes, los cuales miden 4 competencias de seguridad: protección de dispositivos, protección de datos personales, protección de la salud y protección del medio ambiente.

Los 16 ítems de conocimientos/habilidades son tipo prueba objetiva con 4 alternativas de respuesta y sólo una de ellas correcta. Las respuestas se han codificado de forma dicotómica (1= elige la respuesta correcta; $2=$ elige respuesta incorrecta). Por lo tanto, la puntuación máxima del test es de 16 puntos. El estudio piloto realizado con la escala de actitudes, construida en la fase previa, nos posibilita la selección definitiva de 6 ítems.

La prueba aplicada se presenta en el Anexo I.

\section{Procedimiento y aplicación}

Para proceder a la aplicación de la prueba se obtiene el permiso de las autoridades educativas y del Comité ético de la Universidad. Se realiza una versión online de la prueba a través de una web diseñada con esta finalidad que facilita las respuestas de los niños.

Posteriormente se prepara una convocatoria enviada a los centros educativos seleccionados solicitando la participación de los estudiantes de $6^{\circ}$ de Primaria y/o $1^{\circ}$ de Secundaria. Los centros educativos que han colaborado en el estudio se han encargado de obtener los permisos de las familias y de los niños (con protocolos preparados por los investigadores), así como de su aplicación en el horario lectivo.

\section{Análisis de datos}

El análisis de los datos se dirige a comprobar las características psicotécnicas del instrumento, con el fin de conocer su validez y fiabilidad. Para ello se han estudiado de forma diferenciada los ítems del ámbito del conocimiento y habilidad (test de conocimiento y capacidad) y los ítems que conforman la escala de actitudes. Posteriormente, se ha realizado un estudio de la prueba completa, estudiando el posible sesgo en función del género.

El análisis de los datos incluye el análisis descriptivo de los ítems, las correlaciones de los ítems, el análisis de discriminación y fiabilidad de los ítems y el análisis de la fiabilidad y validez estructural de la prueba.

Los análisis se han realizado con el programa SPSS v.21 y el software CORRECTOR 1.2 desarrollado por el Prof. JL Gaviria del Dpto. de Métodos de Investigación de la Universidad Complutense de Madrid. Este software actúa como un complemento de MS-Excel y permite 
realizar análisis de pruebas objetivas y de escalas tipo Likert, aportando información de cada ítem, varianza, correlación biserial-puntual, índice de dificultad, etc.

\section{RESULTADOS}

Análisis de ítems del test de conocimiento y capacidad

\section{Análisis descriptivo de los ítems e índice de dificultad}

En la tabla 1 se pueden observar los datos de cada ítem respecto a su media, desviación típica, asimetría y curtosis. Recordamos que los ítems son dicotómicos (acierto 1/error 0) y el máximo sería 1. Se especifica también el ámbito de la competencia de cada ítem (conocimiento/habilidad).

Tabla 1. Análisis descriptivo de los ítems que componen el test

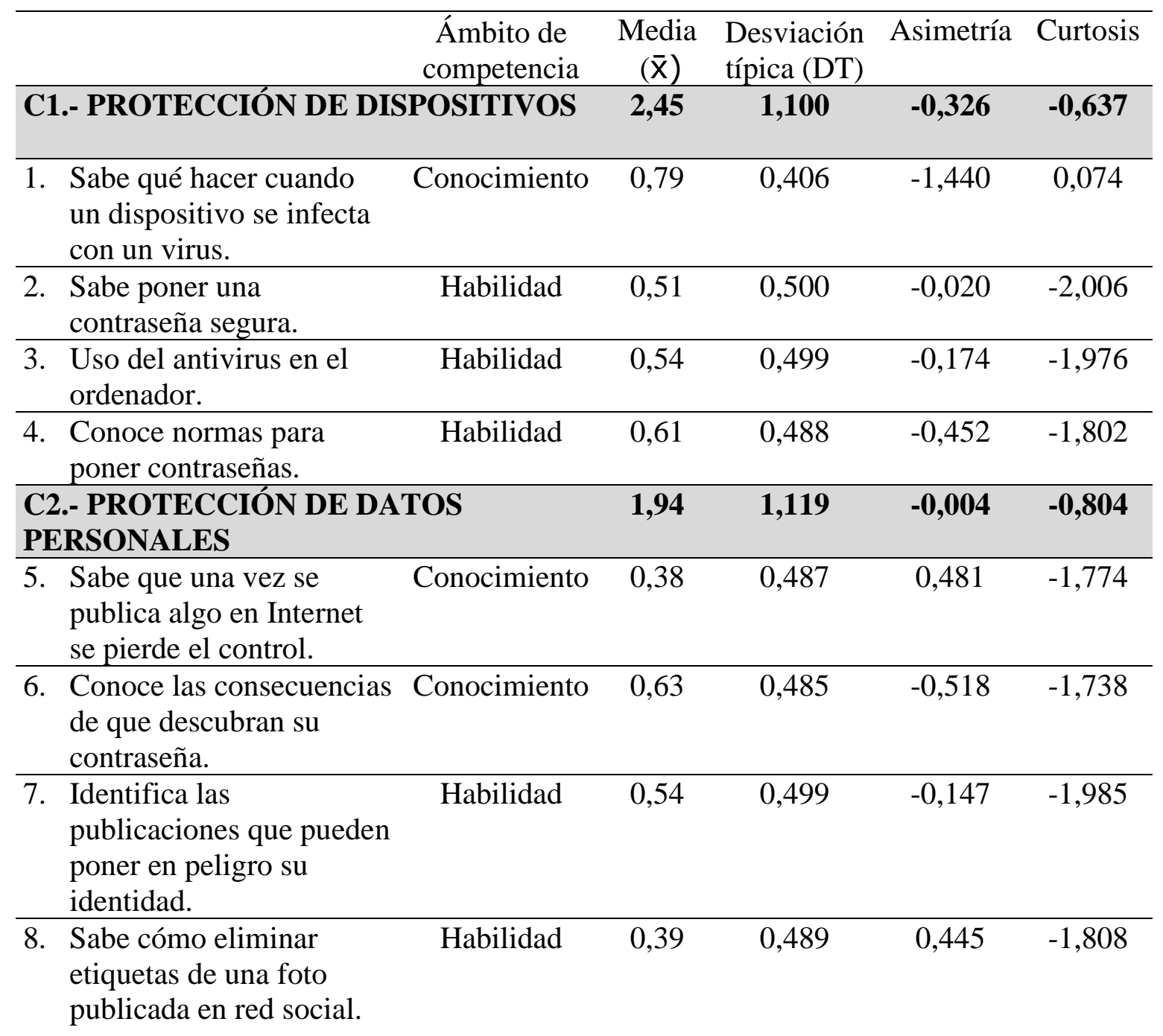

Evaluación de las competencias digitales sobre seguridad de los estudiantes de Educación Básica, García-Valcárcel, A., Salvador, L., Casillas, S. y Basilotta, V. 
RED. Revista de Educación a Distancia. Núm. 61, Artíc. 05, 30-10-2019

DOI: http://dx.doi.org/10.6018/red/61/05

\begin{tabular}{|c|c|c|c|c|c|}
\hline C3.- PROTECCIÓN DE LA & SALUD & 2,76 & 1,118 & $-0,625$ & $-0,423$ \\
\hline $\begin{array}{l}\text { 9. Sabe cómo evitar } \\
\text { problemas de acoso a } \\
\text { través de Internet. }\end{array}$ & Conocimiento & 0,64 & 0,480 & $-0,592$ & $-1,655$ \\
\hline $\begin{array}{l}\text { 10. Juega con los amigos } \\
\text { online de forma positiva }\end{array}$ & Habilidad & 0,83 & 0,380 & $-1,715$ & 0,944 \\
\hline $\begin{array}{l}\text { 11. Mantiene una postura } \\
\text { correcta cuando usa } \\
\text { dispositivos digitales. }\end{array}$ & Habilidad & 0,71 & 0,454 & $0-, 928$ & $-1,143$ \\
\hline $\begin{array}{l}\text { 12. Navega por Internet sin } \\
\text { perder el tiempo. }\end{array}$ & Habilidad & 0,59 & 0,493 & $-0,353$ & $-1,882$ \\
\hline $\begin{array}{l}\text { C4.- PROTECCIÓN DEL M } \\
\text { AMBIENTE }\end{array}$ & EDIO & 1,78 & 0,939 & $-0,181$ & $-0,745$ \\
\hline $\begin{array}{l}\text { 13. Sabe que el consumo de } \\
\text { dispositivos tiene } \\
\text { impacto en el medio } \\
\text { ambiente. }\end{array}$ & Conocimiento & 0,54 & 0,499 & $-0,174$ & $-1,976$ \\
\hline $\begin{array}{l}\text { 14. Conoce el impacto medio } \\
\text { ambiental negativo de la } \\
\text { fabricación de los } \\
\text { dispositivos. } \\
\end{array}$ & Conocimiento & 0,13 & 0,333 & 2,251 & 3,075 \\
\hline $\begin{array}{l}\text { 15. Ahorra energía en el uso } \\
\text { de los dispositivos. }\end{array}$ & Habilidad & 0,40 & 0,491 & 0,395 & $-1,850$ \\
\hline $\begin{array}{l}\text { 16. Es capaz de dejar de } \\
\text { jugar si se siente } \\
\text { nervioso. }\end{array}$ & Habilidad & 0,70 & 0,458 & $-0,884$ & $-1,223$ \\
\hline $\begin{array}{l}\text { TOTAL (max. } 16 \text { puntos) } \\
\mathrm{N}=600\end{array}$ & & 8,93 & 2,925 & $-0,249$ & $-0,446$ \\
\hline
\end{tabular}

La media de los sujetos en el test es de 8,9 puntos, es decir, se sitúa en el entorno de un punto medio de la escala. Analizando la media de cada ítem, encontramos la puntuación mínima de 0,13 (ítem 14) y la máxima de 0,83 (ítem 10), lo que prueba la variabilidad en la dificultad de los ítems, siendo el ítem 14 el más difícil (sólo lo aciertan el 13\% de los sujetos) y el 10 el más fácil (acertado por el 83\%). El contenido de estos ítems hace pensar que los niños juegan con los amigos online de forma positiva y manteniendo buenas relaciones (ítem 10), si bien no son conscientes del impacto medioambiental de la fabricación de los dispositivos electrónicos (ítem 14).

Se observa que algunos ítems $(1,10$ y 14) presentan una asimetría elevada (superior a 1 o 1). En el caso del ítem 1, el 79\% de los niños saben qué hacer si un ordenador se infecta con un virus. Respecto a la curtosis vemos que todos los ítems, excepto el 14, presentan valores inferiores a 3 , por lo que pueden considerarse distribuciones platicúrticas.

Evaluación de las competencias digitales sobre seguridad de los estudiantes de Educación Básica, García-Valcárcel, A., Salvador, L., Casillas, S. y Basilotta, V.

Página 9 de 34 
En la tabla 1 se muestran también los estadísticos de los ítems agrupados en las cuatro competencias identificadas $(\mathrm{C} 1$ a $\mathrm{C} 4)$. Cada una de estas variables se ha creado como suma de las puntuaciones en los 4 ítems que miden la competencia correspondiente. Las puntuaciones medias se sitúan en un punto central de la escala, con una oscilación desde una puntuación de 1,78 para la competencia más baja (protección del entorno) a 2,76 para la competencia más alta (protección de la salud). Se puede concluir que los estudiantes tienen mayores conocimientos y capacidades en primer lugar en lo referente a la protección de la salud, en segundo lugar, en la protección de dispositivos, seguido de la protección de datos personales $\mathrm{y}$, finalmente, en la protección del entorno.

\section{Análisis de correlaciones entre los ítems}

Con el fin de conocer las relaciones entre los ítems del test se llevan a cabo análisis de correlaciones de Pearson entre los 16 elementos. En la mayoría de los casos, las correlaciones son positivas y aunque no son elevadas, sí resultan significativas. Los ítems de conocimiento (sombreados en la tabla 2) presentan correlaciones significativas entre sí, excepto en el caso del ítem 1 con el 5; y el 14 con el 6 y 9. En el caso de los ítems de competencias hay más correlaciones no significativas, tal como se puede observar en la tabla 2.

Los ítems que menos correlacionan con el resto son el ítem 2, 7, 8, 14 y 15. Llama la atención el ítem 14 por sus correlaciones negativas con el resto de los ítems. Mientras que los ítems con mayor número de correlaciones significativas son el 11, 12, 13 y 16, relacionados con las competencias de protección de la salud y del entorno.

Tabla 2. Correlaciones entre los ítems de Conocimiento y Capacidad

\begin{tabular}{|c|c|c|c|c|c|c|c|c|}
\hline & 1 & 2 & 3 & 4 & 5 & 6 & 7 & 8 \\
\hline $\begin{array}{l}\text { Item } \\
1\end{array}$ & 1,00 & $0,11 * *$ & $0,16 * *$ & 0,07 & 0,02 & $0,19 * *$ & $0,13 * *$ & 0,07 \\
\hline $\begin{array}{l}\text { Item } \\
2\end{array}$ & & 1,00 & 0,07 & $0,14 * *$ & $0,14 * *$ & $0,18 * *$ & 0,07 & 0,05 \\
\hline $\begin{array}{l}\text { Item } \\
3\end{array}$ & & & 1,00 & $0,14 * *$ & 0,02 & $0,09 *$ & 0,03 & $0,14 * *$ \\
\hline $\begin{array}{l}\text { Ítem } \\
4\end{array}$ & & & & 1,00 & $0,15 * *$ & $0,16^{* * *}$ & $0,09^{*}$ & $0,12 * *$ \\
\hline $\begin{array}{l}\text { Ítem } \\
5\end{array}$ & & & & & 1,00 & $0,16^{* *}$ & 0,07 & 0,06 \\
\hline $\begin{array}{l}\text { Item } \\
6\end{array}$ & & & & & & 1,00 & $0,20 * *$ & 0,07 \\
\hline $\begin{array}{l}\text { Ítem } \\
7\end{array}$ & & & & & & & 1,00 & 0,04 \\
\hline $\begin{array}{l}\text { Ittem } \\
8\end{array}$ & & & & & & & & 1,00 \\
\hline
\end{tabular}

Evaluación de las competencias digitales sobre seguridad de los estudiantes de Educación Básica, García-Valcárcel, A., Salvador, L., Casillas, S. y Basilotta, V.

Página 10 de 34 
RED. Revista de Educación a Distancia. Núm. 61, Artíc. 05, 30-10-2019

DOI: http://dx.doi.org/10.6018/red/61/05

\begin{tabular}{|c|c|c|c|c|c|c|c|c|}
\hline & 9 & 10 & 11 & 12 & 13 & 14 & 15 & 16 \\
\hline $\begin{array}{l}\text { Ítem } \\
1\end{array}$ & $0,18 * *$ & $0,22 * *$ & $0,16 * *$ & 0,08 & $0,16 * *$ & $-0,11 * *$ & 0,04 & 0,07 \\
\hline $\begin{array}{l}\text { Item } \\
2\end{array}$ & 0,01 & 0,08 & 0,06 & $0,12^{* *}$ & $0,09 *$ & $-0,03$ & 0,03 & $-0,00$ \\
\hline $\begin{array}{l}\text { Item } \\
3\end{array}$ & 0,07 & $0,09 *$ & $0,14 * *$ & $0,13 * *$ & $0,12 * *$ & $-0,11 * *$ & $0,11 * *$ & $0,10^{*}$ \\
\hline $\begin{array}{l}\text { Item } \\
4\end{array}$ & $0,15^{* *}$ & $0,19 * *$ & $0,11 * *$ & $0,16^{* *}$ & $0,12 * *$ & $-0,06$ & $0,09 *$ & $0,12 * *$ \\
\hline $\begin{array}{l}\text { Item } \\
5\end{array}$ & $0,09 *$ & 0,07 & $0,10^{*}$ & $0,140 * *$ & $0,083^{*}$ & $-0,084 *$ & $0,106^{* *}$ & 0,087 \\
\hline $\begin{array}{l}\text { Ítem } \\
6\end{array}$ & $0,17 * *$ & $0,27 * *$ & 0,07 & $0,22 * *$ & $0,26 * *$ & $-0,06$ & 0,02 & $0,13 * *$ \\
\hline $\begin{array}{l}\text { Ítem } \\
7\end{array}$ & $0,11 * *$ & $0,13 * *$ & 0,05 & $0,16 * *$ & $0,17 * *$ & $-0,07$ & 0,06 & $0,10^{*}$ \\
\hline $\begin{array}{l}\text { Item } \\
8\end{array}$ & $0,09 *$ & $0,11 * *$ & $0,11 * *$ & $0,09 *$ & $0,08 *$ & 0,00 & $0,113 * *$ & $0,10^{* *}$ \\
\hline
\end{tabular}

\begin{tabular}{|c|c|c|c|c|c|c|c|c|}
\hline & 9 & 10 & 11 & 12 & 13 & 14 & 15 & 16 \\
\hline $\begin{array}{l}\text { Ittem } \\
9\end{array}$ & 1,00 & $0,20 * *$ & $0,13 * *$ & $0,13 * *$ & $0,16^{* *}$ & $-0,06$ & 0,06 & $0,17 * *$ \\
\hline $\begin{array}{l}\text { Ítem } \\
10\end{array}$ & & 1,00 & $0,19 * *$ & $0,25^{* *}$ & $0,17 * *$ & $-0,09 *$ & 0,06 & $0,20 * *$ \\
\hline $\begin{array}{l}\text { Item } \\
11\end{array}$ & & & 1,00 & $0,18^{* *}$ & $0,09 *$ & $-0,15 * *$ & $0,09 *$ & $0,26 * *$ \\
\hline $\begin{array}{l}\text { Item } \\
12\end{array}$ & & & & 1,00 & $0,13 * *$ & $-0,07$ & 0,03 & $0,20 * *$ \\
\hline $\begin{array}{l}\text { Ítem } \\
13\end{array}$ & & & & & 1,00 & $-0,12 * *$ & $0,13^{* *}$ & $0,16 * *$ \\
\hline $\begin{array}{l}\text { Ítem } \\
14\end{array}$ & & & & & & 1,00 & $-0,12 * *$ & $-0,08 *$ \\
\hline $\begin{array}{l}\text { Ítem } \\
15\end{array}$ & & & & & & & 1,00 & $0,09^{*}$ \\
\hline $\begin{array}{l}\text { Ítem } \\
16\end{array}$ & & & & & & & & 1,00 \\
\hline
\end{tabular}

Analizando las correlaciones entre las cuatro competencias (tabla 3), se observan valores moderados, pero altamente significativos entre todas ellas, dado el tamaño de la muestra. También se observan correlaciones significativas, aunque los valores son bajos, entre las competencias y la actitud considerando la puntuación total en la escala (tabla 4).

Evaluación de las competencias digitales sobre seguridad de los estudiantes de Educación Básica, García-Valcárcel, A., Salvador, L., Casillas, S. y Basilotta, V.

Página 11 de 34 
RED. Revista de Educación a Distancia. Núm. 61, Artíc. 05, 30-10-2019

DOI: http://dx.doi.org/10.6018/red/61/05

Tabla 3. Correlaciones entre competencias

\begin{tabular}{lcccc}
\hline & $\mathrm{C} 1$ & $\mathrm{C} 2$ & $\mathrm{C} 3$ & $\mathrm{C} 4$ \\
\hline $\begin{array}{c}\mathrm{C} 1 \text { - Protección } \\
\text { dispositivos }\end{array}$ & 1 & $0,311^{* *}$ & $0,330^{* * *}$ & $0,179^{* *}$ \\
\hline $\begin{array}{c}\mathrm{C} 2 \text { - Protección de datos } \\
\text { personales }\end{array}$ & 1 & $0,348^{* * *}$ & $0,268^{* *}$ \\
\hline $\begin{array}{c}\mathrm{C} 3 \text { - Protección de la } \\
\text { salud }\end{array}$ & & 1 & $0,278^{* *}$ \\
\hline $\begin{array}{c}\mathrm{C} 4 \text { - Protección del } \\
\text { entorno }\end{array}$ & & & 1 \\
\hline$*$ Correlación significativa al 0,05 & $* *$ Correlación significativa al 0,01
\end{tabular}

Tabla 4. Correlaciones entre competencias y actitud

\begin{tabular}{lc}
\hline & TOTAL ACTITUD \\
\hline $\begin{array}{c}\text { C1 - Protección } \\
\text { dispositivos }\end{array}$ & $0,113^{* *}$ \\
\hline $\begin{array}{c}\text { C2 - Protección de datos } \\
\text { personales }\end{array}$ & $0,138^{* *}$ \\
\hline $\begin{array}{c}\text { C3 - Protección de la } \\
\text { salud }\end{array}$ & $0,156^{* *}$ \\
\hline $\begin{array}{c}\text { C4 - Protección del } \\
\text { entorno }\end{array}$ & $0,189^{* *}$ \\
\hline$* *$ Correlación significativa al 0,01
\end{tabular}

\section{Análisis de discriminación, dificultad y fiabilidad de los ítems}

En la tabla 5 se muestran los datos estadísticos de cada uno de los ítems de conocimiento y capacidad que permiten conocer el índice de discriminación de cada ítem (correlación biserial puntual), el índice de dificultad, la media y varianza de la escala si se suprimiera el ítem, la correlación de los elementos corregida y la fiabilidad de la escala si se suprime el ítem.

Tabla 5. Estadísticas de ítems de conocimiento y capacidad

\begin{tabular}{lcccccc}
\hline $\begin{array}{c}\text { Índice de } \\
\text { discriminació } \\
\mathrm{n}(\mathrm{rbp})\end{array}$ & $\begin{array}{c}\text { Índice de } \\
\text { dificultad } \\
(\% \text { de } \\
\text { acierto) }\end{array}$ & $\begin{array}{c}\text { Media de } \\
\text { escala si el } \\
\text { elemento se } \\
\text { ha suprimido ha suprimido }\end{array}$ & $\begin{array}{c}\text { Varianza de } \\
\text { escala si el }\end{array}$ & $\begin{array}{c}\text { Correlación } \\
\text { elemento- } \\
\text { total } \\
\text { corregida }\end{array}$ & $\begin{array}{c}\text { Alfa de } \\
\text { Cronbach si } \\
\text { el elemento } \\
\text { se ha } \\
\text { suprimido }\end{array}$ \\
\hline Ítem 1 & 0,39 & $79,2 \%$ & 8,13 & 7,789 & 0,266 & 0,613 \\
Ítem 2 & 0,35 & $50,5 \%$ & 8,42 & 7,783 & 0,187 & 0,625 \\
\hline
\end{tabular}

Evaluación de las competencias digitales sobre seguridad de los estudiantes de Educación Básica, García-Valcárcel, A., Salvador, L., Casillas, S. y Basilotta, V.

Página 12 de 34 
RED. Revista de Educación a Distancia. Núm. 61, Artíc. 05, 30-10-2019

DOI: http://dx.doi.org/10.6018/red/61/05

\begin{tabular}{lcccccc}
\hline Ítem 3 & 0,38 & $54,3 \%$ & 8,38 & 7,685 & 0,225 & 0,619 \\
Ítem 4 & 0,45 & $61,0 \%$ & 8,32 & 7,508 & 0,303 & 0,607 \\
Ítem 5 & 0,37 & $38,3 \%$ & 8,54 & 7,734 & 0,216 & 0,620 \\
Ítem 6 & 0,51 & $62,5 \%$ & 8,30 & 7,349 & 0,370 & 0,596 \\
Ítem 7 & 0,39 & $53,7 \%$ & 8,39 & 7,664 & 0,233 & 0,618 \\
Ítem 8 & 0,37 & $39,2 \%$ & 8,53 & 7,738 & 0,213 & 0,620 \\
Ítem 9 & 0,43 & $64,2 \%$ & 8,28 & 7,582 & 0,282 & 0,610 \\
Ítem 10 & 0,48 & $82,5 \%$ & 8,10 & 7,636 & 0,369 & 0,601 \\
Ítem 11 & 0,41 & $71,0 \%$ & 8,22 & 7,665 & 0,273 & 0,612 \\
Ítem 12 & 0,48 & $58,7 \%$ & 8,34 & 7,403 & 0,340 & 0,601 \\
Ítem 13 & 0,46 & $54,3 \%$ & 8,38 & 7,455 & 0,313 & 0,605 \\
Ítem 14 & $-0,08$ & $12,7 \%$ & 8,80 & 8,829 & $-0,194$ & 0,661 \\
Ítem 15 & 0,32 & $40,3 \%$ & 8,52 & 7,873 & 0,161 & 0,628 \\
Ítem 16 & 0,44 & $70,2 \%$ & 8,22 & 7,599 & 0,296 & 0,608 \\
\hline
\end{tabular}

En función de los porcentajes de acierto (índice de dificultad), podemos establecer una distribución de los ítems en 3 niveles de dificultad o nivel competencial (ver tabla 6).

Tabla 6. Nivel de dificultad de los ítems del test de conocimiento y capacidad

\begin{tabular}{lllll}
\hline Ítems & $\%$ de acierto & Criterio & Calificación & Nivel \\
\hline $1,10,11,16$ & $79,83,71,70$ & $>70$ & Muy fácil & Básico (7 ítems) \\
$4,6,9$ & $61,63,64$ & $60-70$ & Fácil & \\
\hline $2,3,7,13,12$ & $50,54,54,54$, & $40-60$ & Moderado & Intermedio (5 ítems) \\
\hline 59 & $38,39,40$ & $30-40$ & Difícil & \multirow{2}{*}{ Avanzado (4 ítems) } \\
\hline $5,8,15,14$ & 13 & $<30$ & Muy difícil & \\
\hline
\end{tabular}

El análisis de los ítems y su aportación a fiabilidad de la prueba aconsejarían la supresión del ítem 14, por su correlación negativa y el aumento de la fiabilidad de la escala en caso de suprimirse (Alfa de Cronbach $=0,66$ ).

En el gráfico 1 se presentan los ítems situados en las coordenadas que representan la dificultad del ítem y el índice de discriminación (correlación biserial puntual), donde se puede ver que la mayoría de los ítems se sitúan en la zona objetivo, con un índice de dificultad media y adecuados índices de discriminación, exceptuando algunos ítems muy fáciles $(1,10$, 11 y 16) y el ítem 14 que queda claramente al margen en la zona de discriminación negativa. Los ítems fáciles se justifican desde un punto de vista conceptual por tratarse de cuestiones que son relevantes y básicas en la evaluación de las competencias, por lo que se comprueba que la mayoría de los niños han adquirido esos conocimientos y capacidades. Sin embargo, el ítem 14 debe ser objeto de modificación o eliminación.

Evaluación de las competencias digitales sobre seguridad de los estudiantes de Educación Básica, García-Valcárcel, A., Salvador, L., Casillas, S. y Basilotta, V.

Página 13 de 34 
Gráfico 1. Distribución de los ítems en función de índices de dificultad/facilidad y discriminación $\left(\mathrm{r}_{\mathrm{bp}}\right)$

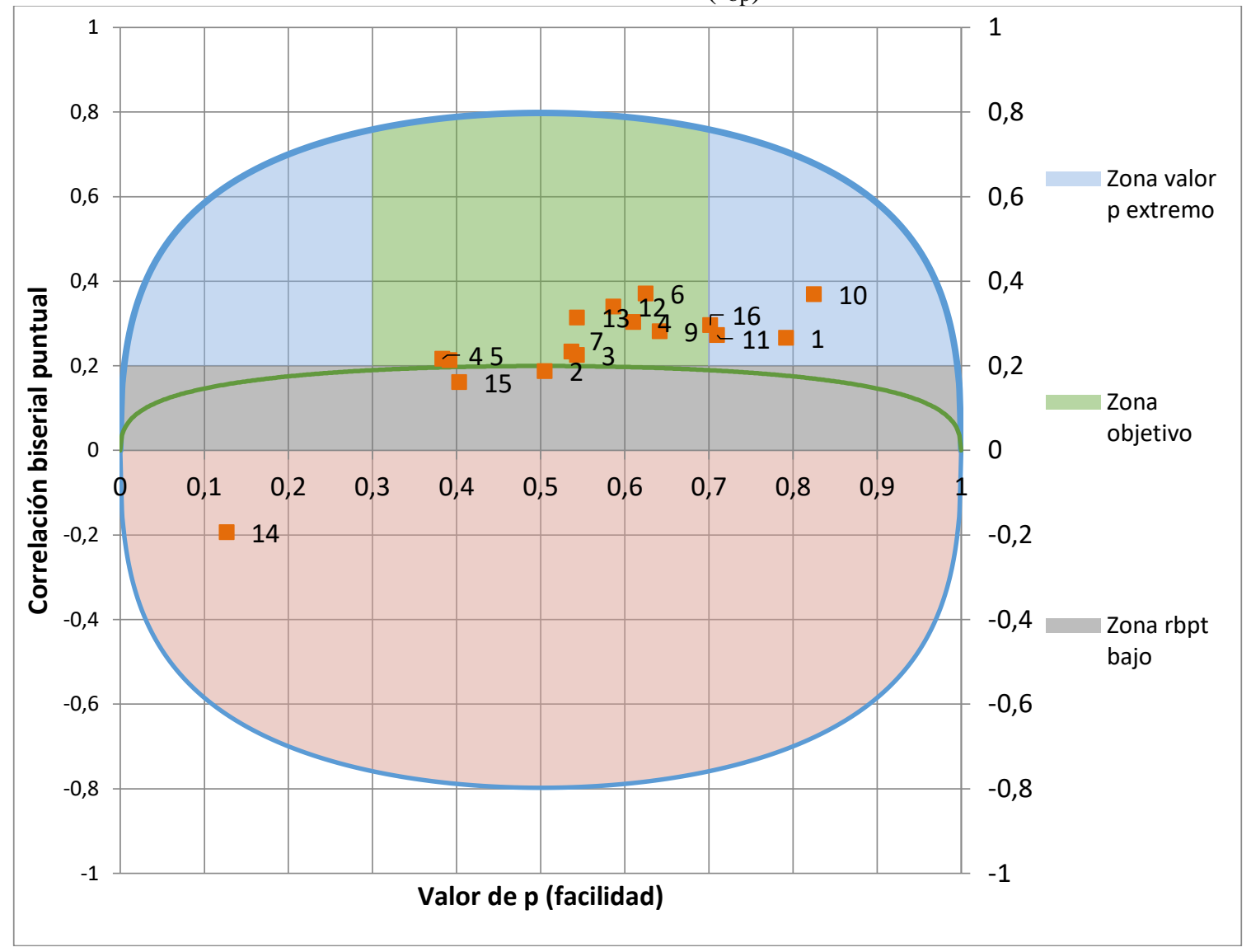

\section{Análisis de fiabilidad del test}

Para el estudio de la fiabilidad del test de conocimientos y capacidades se ha calculado la correlación $\mathrm{KR}_{20}$ considerando el carácter dicotómico de los 16 ítems. El valor alfa de Cronbach $=0,631$. Este índice de consistencia interna del test puede considerarse pertinente para este tipo de instrumentos de evaluación de competencias. Contrastada la hipótesis de significación (Muñiz, 1992: 60), podemos determinar que el valor alfa obtenido es significativo.

Análisis de ítems de la escala de actitudes

Las actitudes han sido valoradas a través de una escala Likert (1 muy en desacuerdo, 5 muy de acuerdo) compuesta por los siguientes ítems:

1. Sólo se deben compartir las contraseñas con los padres o tutores.

2. Soy consciente de que las tecnologías pueden crear adicción

Evaluación de las competencias digitales sobre seguridad de los estudiantes de Educación Básica, García-Valcárcel, A., Salvador, L., Casillas, S. y Basilotta, V.

Página 14 de 34 
3. Subir fotos a Internet y compartir información personal y familiar puede ser peligroso.

4. Valoro los dispositivos tecnológicos que respetan el medio ambiente.

5. En lugares públicos procuro utilizar la wifi cuando es segura.

6. Soy consciente de que los recursos naturales con los que se fabrican los móviles son limitados y pueden agotarse.

\section{Estadísticos descriptivos de la escala de actitudes}

A continuación, se muestran los estadísticos descriptivos de los ítems que conforman la escala (ver tabla 7), en concreto las puntuaciones mínimas y máximas obtenidas, la media, desviación típica, asimetría y curtosis.

Tabla 7. Estadísticos descriptivos ítems de actitudes

(Dimensión actitudinal de la competencia)

\begin{tabular}{lcccccc}
\hline $\begin{array}{l}\text { Items de } \\
\text { actitud }\end{array}$ & Mínimo & Máximo & Media & $\begin{array}{c}\text { Desviación } \\
\text { estándar }\end{array}$ & Asimetría & Curtosis \\
\hline A- 1 & 1 & 5 & 4,22 & 1,169 & $-1,526$ & 1,399 \\
A- 2 & 1 & 5 & 4,49 & 0,830 & $-2,004$ & 4,483 \\
A- 3 & 1 & 5 & 4,58 & 0,860 & $-2,516$ & 6,514 \\
A- 4 & 1 & 5 & 4,27 & 0,941 & $-1,366$ & 1,631 \\
A- 5 & 1 & 5 & 4,24 & 1,056 & $-1,572$ & 2,192 \\
A- 6 & 1 & 5 & 4,28 & 0,967 & $-1,517$ & 2,192 \\
\hline TOTAL & 6 & 30 & 26,07 & 3,804 & $-2,048$ & 7,337 \\
N=600 & & & & & & \\
\hline
\end{tabular}

Se observa que las medias en todos los ítems son elevadas, especialmente las de los ítems 2 y 3 ("Soy consciente de que las tecnologías pueden crear adicción" y" Subir fotos a Internet y compartir información personal y familiar puede ser peligroso"), mostrando una elevada asimetría. La curtosis leptocúrtica (mayor a 3) de estos ítems nos indica que existe una gran concentración de los valores en torno a su media.

La puntuación media en el total de la escala se encuentra en 26,07 , lo que demuestra una actitud muy positiva en los jóvenes en el ámbito de la seguridad digital.

\section{Análisis de correlaciones de los ítems de actitudes}

Se ha estudiado la relación entre los ítems de la escala de actitudes y se puede concluir que todos los ítems muestran correlaciones significativas con el resto de elementos y con el total de la escala, siendo las correlaciones con el total las más elevadas, superando en casi todos los casos el valor de 0,60 . Ver tabla 8 .

Se observa así mismo correlaciones más altas entre los ítems 4, 5 y 6 relacionados con la protección del medio ambiente. 
Tabla 8. Análisis de correlaciones entre los ítems de actitudes

\begin{tabular}{|c|c|c|c|c|c|c|c|}
\hline Ítems & 1 & 2 & 3 & 4 & 5 & 6 & Total \\
\hline A- 1 & 1 & $0,225 * *$ & $0,157^{* *}$ & $0,273^{* *}$ & $0,210 * *$ & $0,276^{* *}$ & $0,585^{* * *}$ \\
\hline A- 2 & & 1 & $0,461^{* *}$ & $0,346^{* *}$ & $0,281^{* *}$ & $0,390 * *$ & $0,652 * *$ \\
\hline A- 3 & & & 1 & $0,337 * *$ & $0,347 * *$ & $0,305^{* *}$ & $0,630 * *$ \\
\hline A- 4 & & & & 1 & $0,408 * *$ & $0,443 * *$ & $0,706 * *$ \\
\hline A- 5 & & & & & 1 & $0,365^{* *}$ & $0,673 * *$ \\
\hline A- 6 & & & & & & 1 & $0,701 * *$ \\
\hline
\end{tabular}

\section{Análisis de discriminación y fiabilidad de los ítems}

Para calcular el índice de discriminación de cada ítem de actitudes en base a la correlación biserial puntual, se ha dicotomizado la variable, de modo que las puntuaciones 4 y 5 se han considerado como "actitud positiva" y el resto de las puntuaciones (1, 2 y 3$)$ como "actitud no positiva". Los datos se presentan en la tabla 9. Se puede observar que las correlaciones son positivas, con un índice de discriminación adecuado.

Tabla 9. Estadísticas de total de ítems de actitudes

\begin{tabular}{ccccccc}
\hline & $\begin{array}{c}\text { Índice de } \\
\text { discrimina- } \\
\text { ción (rbp) }\end{array}$ & $\begin{array}{c}\text { Media de } \\
\text { escala si el } \\
\text { elemento se } \\
\text { ha suprimido }\end{array}$ & $\begin{array}{c}\text { Varianza de } \\
\text { escala si el } \\
\text { elemento se } \\
\text { ha } \\
\text { suprimido }\end{array}$ & $\begin{array}{c}\text { Correlación } \\
\text { total de } \\
\text { elementos } \\
\text { corregida }\end{array}$ & $\begin{array}{c}\text { Correlación } \\
\text { múltiple al } \\
\text { cuadrado }\end{array}$ & $\begin{array}{c}\text { Alfa de } \\
\text { Cronbach si } \\
\text { el elemento } \\
\text { se ha }\end{array}$ \\
\hline A- 1 & 0,522 & 21,86 & 10,651 & 0,322 & 0,115 & 0,738 \\
A- 2 & 0,542 & 21,58 & 11,068 & 0,491 & 0,294 & 0,681 \\
A- 3 & 0,548 & 21,49 & 11,118 & 0,455 & 0,273 & 0,689 \\
A- 4 & 0,577 & 21,80 & 10,317 & 0,541 & 0,306 & 0,663 \\
A- 5 & 0,591 & 21,84 & 10,194 & 0,468 & 0,245 & 0,684 \\
A-6 & 0,580 & 21,80 & 10,263 & 0,528 & 0,297 & 0,666 \\
\hline
\end{tabular}

Se ha calculado la fiabilidad de la escala de actitudes y se ha obtenido el valor de Alfa de Cronbach $=0,725$, lo que puede considerarse una fiabilidad muy elevada, dado el reducido número de ítems.

Evaluación de las competencias digitales sobre seguridad de los estudiantes de Educación Básica, García-Valcárcel, A., Salvador, L., Casillas, S. y Basilotta, V.

Página 16 de 34 


\section{Análisis de la prueba completa}

La prueba completa se compone de los tres ámbitos de las competencias (conocimiento, capacidad y actitud), por lo que han sido tenidos en cuenta los 22 ítems, 6 de conocimiento, 10 de capacidad y 6 de actitud. Para el análisis de la prueba completa, las puntuaciones de los ítems de actitudes se han dicotomizado, como se hizo para el análisis de los ítems. De este modo la puntuación máxima en esta variable es 6 , manteniendo la misma escala de medida en los 22 ítems.

\section{Estadísticos descriptivos de la prueba completa}

En la tabla 10 se pone de manifiesto que las actitudes mostradas por los niños/as alcanzan un nivel de desarrollo muy superior al ámbito de los conocimientos y capacidades. Estos últimos se sitúan en un punto medio de la escala, mientras las actitudes alcanzan un nivel alto. La puntuación global es de 14 puntos en una escala de 0 a 22 puntos.

La desviación típica del total de la prueba pone de manifiesto la variabilidad que se atribuye a la prueba, siendo capaz de diferenciar entre los diferentes niveles de competencia de los sujetos.

Tabla 10. Resumen de datos descriptivos de los 3 ámbitos de las competencias

\begin{tabular}{lcccc}
\hline & $\begin{array}{c}\text { Mínimo } \\
\text { obtenido }\end{array}$ & $\begin{array}{c}\text { Máximo } \\
\text { obtenido }\end{array}$ & Media & $\begin{array}{c}\text { Desviación } \\
\text { típica }\end{array}$ \\
\hline $\begin{array}{l}\text { CONOCIMIENTO } \\
\text { (máx. 6) }\end{array}$ & 0 & 6 & 3,11 & 1,321 \\
\hline $\begin{array}{l}\text { CAPACIDAD } \\
\text { (máx. 10) }\end{array}$ & 0 & 10 & 5,81 & 2,115 \\
\hline $\begin{array}{l}\text { ACTITUD } \\
\text { (máx. 6) }\end{array}$ & 0 & 6 & 5,05 & 1,380 \\
\hline $\begin{array}{l}\text { PRUEBA COMPLETA } \\
\text { (máx. 22)* N=600 }\end{array}$ & 3 & 21 & 13,98 & 3,490 \\
\hline
\end{tabular}

* Indica la puntuación teórica máxima

\section{Fiabilidad y validez de la prueba}

Recordemos que ya se presentó la fiabilidad del test de conocimiento y capacidad (16 ítems) con un valor Alfa de Cronbach =0,63. En segundo lugar, se ha calculado la fiabilidad de la escala de actitudes, con un Alfa de Cronbach $=0,72$. Al considerar el conjunto de 22 ítems, es decir, la prueba completa se ha obtenido una fiabilidad Alfa de Cronbach $=0,68$. Por último, se ha calculado la fiabilidad de la prueba si se eliminara el ítem 14, tal como se ha sugerido a lo largo del texto, en cuyo caso el Alfa de Cronbach se situaría en 0,70. 
En el estudio de validez de la prueba completa hemos considerado dos tipos de validez: de contenido y estructural. A este respecto, consideramos que los ítems de la prueba constituyen una muestra representativa del contenido a evaluar, ya que se ajustan a un modelo de indicadores de las competencias del modelo DigComp elaborado por el equipo de investigación y validado por expertos, tal como ya se indicó anteriormente (se presenta en el Anexo II). En base al modelo de indicadores ajustados a las edades de los sujetos de referencia, se han formulado los ítems de la prueba y se han sometido a juicio de expertos y grupos de discusión hasta llegar a la formulación final en un proceso de reformulación de los enunciados y respuestas de los ítems. De este modo, el conjunto de ítems de la prueba ha sido validado para medir los conocimientos, capacidades y actitudes del área competencial de Seguridad, siguiendo las pautas del modelo teórico-conceptual DigComp. Por otra parte, los análisis de los ítems han demostrado su capacidad de discriminación y ajuste a la población de referencia, exceptuando el ítem 14 que, como ya se ha comentado, debe ser reformulado.

Para el estudio de la validez estructural se ha llevado a cabo un análisis factorial de componentes principales, tomando como variables las 4 competencias de conocimientocapacidad y los 6 ítems de actitudes. El análisis de las condiciones previas para llevar a cabo el análisis factorial nos ha proporcionado un valor KMO de 0,787 por lo que al estar próximo a 0,80 puede considerarse una muestra adecuada. El índice de esfericidad de Barlett es altamente significativo (con un valor de Chi-cuadrado de 985,81, con 45 grados de libertad, que resulta significativo al 0,000 ), lo que muestra la relación lineal entre las variables. Hemos comprobado igualmente que la asimetría de cada uno de los ítems tomaba valores comprendidos entre -1 y +1 , lo que legitima la realización del análisis.

Mediante el análisis de componentes principales se hallan los valores $\lambda$ para cada uno de los componentes y se retienen los factores cuyo valor $\lambda \geq 1$. El primer factor explica el $28,77 \%$ de la varianza y el segundo añade 16,66, de modo que los dos primeros factores explican el $45,43 \%$ de la varianza de la matriz factorial. En la tabla 11 de matriz de componentes vemos claramente reflejados la vinculación de los ítems de actitudes con el primer factor y los de competencias conocimiento/capacidad con el segundo factor.

Tabla 11. Matriz de componentes principales

\begin{tabular}{lcc}
\hline & \multicolumn{2}{c}{ Componentes } \\
\hline \multicolumn{1}{c}{ Variables } & 1 & 2 \\
\hline C1- Protección dispositivo & 0,320 & $\mathbf{0 , 5 7 9}$ \\
C2- Protección datos personales & 0,372 & $\mathbf{0 , 6 2 5}$ \\
C3- Protección salud & 0,397 & $\mathbf{0 , 6 2 6}$ \\
C4-Protección medio ambiente & 0,396 & $\mathbf{0 , 4 2 3}$ \\
\hline A- 1 & $\mathbf{0 , 4 6 9}$ & $-0,125$ \\
A- 2 & $\mathbf{0 , 6 6 3}$ & $-0,168$ \\
A- 3 & $\mathbf{0 , 6 6 9}$ & $-0,070$ \\
A- 4 & $\mathbf{0 , 6 6 0}$ & $-0,329$ \\
A- 5 & $\mathbf{0 , 5 8 5}$ & $-0,355$ \\
A- 6 & $\mathbf{0 , 6 6 1}$ & $-0,291$ \\
\hline
\end{tabular}

Evaluación de las competencias digitales sobre seguridad de los estudiantes de Educación Básica, García-Valcárcel, A., Salvador, L., Casillas, S. y Basilotta, V.

Página 18 de 34 
Por último, en el estudio de las características de la prueba hemos considerado importante comprobar que los ítems no tienen sesgo en función de las diferencias en función del género. Para ello hemos calculado los valores de Chi cuadrado en tablas cruzadas para cada uno de los ítems de la prueba. Los resultados evidencian que no hay diferencias significativas considerando la variable género, excepto en el ítem 16, con mayor proporción de aciertos en las chicas (56\% frente a $44 \%$ ). Estos resultados nos permiten concluir que se trata de una prueba totalmente válida para ambos colectivos.

\section{DISCUSIÓN Y CONCLUSIONES}

La evaluación de las competencias digitales de los escolares al término de la etapa educativa de Primaria resulta de gran relevancia, especialmente el área de seguridad en el uso de Internet, para evitar posibles problemas con los que se pueden encontrar los menores cuando comienzan a utilizar dispositivos móviles con acceso a la red, lo cual ocurre en España entre los 12 y 14 años (INE, 2018).

Para ello es necesario disponer de pruebas que permitan conocer los conocimientos, habilidades y actitudes, como ámbitos de la competencia, que poseen los jóvenes, de modo más objetivo que la propia autopercepción. En este sentido, se ha analizado una prueba diseñada específicamente para este fin, tomando como modelo de referencia el DigComp (Ferrari, 2013) y se puede concluir que es una prueba válida y fiable que permite clasificar adecuadamente a los sujetos en base a su nivel competencial.

Las competencias que se han contemplado para la evaluación son cuatro: protección de los dispositivos, de los datos personales, de la salud y del medio ambiente. Las correlaciones entre las mismas son significativas al 0,01. El análisis factorial muestra dos factores claramente diferenciados, el primero relacionado con los conocimientos y habilidades y, el segundo, con las actitudes. Los análisis de los ítems se han realizado de forma diferenciada, considerando la tipología de los ítems, en un caso tipo prueba objetiva y en el otro tipo escala Likert. Se puede concluir que los ítems poseen un buen nivel de discriminación y son equilibrados en el nivel de dificultad, a excepción de un ítem que debe modificarse dada su excesiva dificultad y escasa discriminación.

La prueba se compone de ítems de diferente nivel competencial:

- $\quad$ Nivel básico: 7 ítems (3 fáciles y 4 muy fáciles; porcentaje $>60 \%$ de aciertos).

- Nivel intermedio: 5 ítems (dificultad moderada; porcentajes entre 40 y $60 \%$ de aciertos).

- $\quad$ Nivel avanzado: 4 ítems (3 difíciles y 1 muy difícil; porcentaje <40\% de aciertos).

Una vez aplicada la prueba a una muestra de 600 escolares al finalizar la educación Primaria, encontramos que el nivel de competencias en seguridad es moderado $(\overline{\mathrm{X}}=13,98$ en una escala de 0 a 22; DT=3,49). Las puntuaciones en conocimientos y habilidad son más bajas que en actitudes. En conocimientos se observa una puntuación $\bar{x}=3,11 ; \mathrm{DT}=1,32$ (escala de 0 a 6 ) 
y en capacidad encontramos una $\bar{x}=5,81$; DT $=2,11$ (escala de 0 a 10); mientras que en actitudes se sitúa en $\overline{\mathrm{X}}=5,05 ; \mathrm{DT}=1,38$ (escala de 0 a 6 ).

Estos resultados están en la línea de estudios similares (Colás-Bravo, Conde-Jiménez y Reyes de Cózar, 2017). Estos autores detectan diferencias significativas en función de si el alumnado tiene internet en casa, la edad en la que empezó a usar el ordenador y si han recibido portátiles en los centros educativos. Por su parte, Villegas et al. (2017) estudian el uso de las TIC en la vida diaria y en la escuela. Los resultados muestran que los estudiantes hacen uso moderado de las TIC y no hay diferencias significativas en cuanto al sexo y a tener computadora en casa, o no, pero sí en el acceso a internet. El estudio concluye que los alumnos utilizan las TIC más para actividades de esparcimiento que para labores escolares y que sus competencias al respecto son limitadas.

Como resultados de la evaluación, se pone de manifiesto la necesidad de incidir en la adquisición de este tipo de competencias por parte de los estudiantes, algunas conductas que tienen que ver con la salud deben ser reforzadas tales como no comunicarse con personas desconocidas, jugar online de forma saludable, prevenir adicciones (Zhitomirsky-Geffet y Blau, 2016) mantener posturas adecuadas o no perder el tiempo al navegar por Internet. También se requiere mayor formación para hacer un uso de los dispositivos que respete el medio ambiente, siendo conscientes del impacto negativo del cambio frecuente de móvil, usando opciones para ahorrar energía, etc.

Para terminar, señalar algunas limitaciones del estudio relacionadas con las posibles dificultades que pueden tener los niños/as en comprender las preguntas y respuestas ofrecidas en la prueba, lo cual puede interferir de alguna manera en las puntuaciones obtenidas. Resultaría pertinente establecer otras estrategias complementarias que permitan comprobar, de forma práctica a través de tareas específicas, las habilidades de los jóvenes.

Presentación del artículo: 15 de julio de 2019

Fecha de aprobación: 8 de noviembre de 2019

Fecha de publicación: 30 de noviembre de 2019

García-Valcárcel, A., Salvador, L., Casillas, S. y Basilotta, V. (2019). Evaluación de las competencias digitales sobre seguridad de los estudiantes de Educación Básica. RED. Revista Educación a Distancia, 61. DOI: http://dx.doi.org/10.6018/red/61/05

\section{Financiación}

El Proyecto "Competencia digital en estudiantes de educación obligatoria. Entornos sociofamiliares, procesos de apropiación y propuestas de e-inclusión” (CDEPI) es una investigación financiada por el Ministerio de Economía y Competitividad (Ref.: EDU201567975-C3-1-P) y por el Fondo Europeo de Desarrollo Regional (FEDER).

\section{Referencias bibliográficas}

Evaluación de las competencias digitales sobre seguridad de los estudiantes de Educación Básica, García-Valcárcel, A., Salvador, L., Casillas, S. y Basilotta, V.

Página 20 de 34 
Adell, J. (2010). La competencia digital. XXIV Jornadas Pedagógicas de Barakaldo, Bilbao. Recuperado de http://www.slideshare.net/bgune20/1-competencias-tic-alumnos5503002

Aesaert, K. y Van Braak, J. (2014). Exploring factors related to primary school pupils' ICT self-efficacy: A multilevel approach. Computers in Human Behavior, 41, 327-341.

Aesaert, K., Van Braak, J., Van Nijlen, D. y Vanderlinde, R. (2015). Primary school pupils' ICT competences: Extensive model and scale Development. Computers \& Education, 81, 326-344.

Alonso, A. (2012). El desarrollo del concepto de competencia digital en el currículum de las enseñanzas obligatorias en Galicia. Innovación Educativa, 21, pp. 151-159

Aguaded, J. I. y Tirado, R. (2008). Los centros TIC y sus repercusiones didácticas en primaria y secundaria en Andalucía. Educar 41, 61-90.

Area, M. (2012). La alfabetización en la sociedad digital. En M. Area, A. Gutiérrez y M. Á. Marzal, Alfabetización digital y competencias informacionales (pp. 3-42). Barcelona: Fundación Telefónica.

Bawden, D. (2008). Origins and Concepts of Digital Literacy. En C. Lankshear y M. Knobel (Eds.), Digital Literacies: Concepts, Policies and Practices (pp. 17-32). New York: Peter Lang.

Calvani, A.; Fini, A.; Ranieri, M. y Picci, P. (2012). Are young generations in secondary school digitally competent? A study on Italian teenagers. Computers \& Education, 58(2), 797-807.

Cameron, L.; Wise, S. L. y Lottridge, S. M. (2007). The development and validation of the information literacy test. College \& Research Libraries, 68(3), 229-237.

Cánovas, G.; García de Pablo, A.; Oliaga, A. y Aboy, I. (2014). Menores de Edad y Conectividad Móvil en España: Tablets y Smartphones. Centro de Seguridad en Internet para los Menores en España: PROTEGELES. Recuperado de http://www.diainternetsegura.es/descargas/estudio_movil_smartphones_tablets_v2c.pd $\mathrm{f}$

Caridad, M. y Marzal, M. (2006). Políticas de información y alfabetización en información como medios de la inclusión social desde la óptica europea. Inclusão Social, Brasília, $1(2), 31-43$.

Carrera, F. X., Vaquero, E. y Balsells, M. A. (2011). Instrumento de evaluación de competencias digitales para adolescentes en riesgo social. Edutec: revista electrónica de tecnología educativa, 35, 1-25.

Castro, M. (2010). ¿Qué sabemos de la medida de las competencias? Características y problemas psicométricos en la evaluación de competencias, Bordón, 63(1), 109-123.

Clarke, J. y Dede, C. (2010). Assessment, technology, and change. Journal of Research on Technology in Education, 42(3), 309-328.

Claro, M., Cabello, T., San Martín, E. y Nussbaum, M. (2015). Comparing marginal effects of Chilean students' economic, social and cultural status on digital versus reading and mathematics performance. Computers \& Education, 82, 1-10.

Code, J.; Clarke-Midura, J.; Zap, N. y Dede, C. (2011). Virtual performance assessment in immersive virtual environments. En H. Wang, Interactivity in elearning: Case studies and frameworks (pp. 230-252). Hershey, PA: Information Science Reference.

Evaluación de las competencias digitales sobre seguridad de los estudiantes de Educación Básica, García-Valcárcel, A., Salvador, L., Casillas, S. y Basilotta, V.

Página 21 de 34 
Colás-Bravo, P., Conde-Jimenez, J., \& Reyes-de Cózar, S. (2017). Competencias digitales del alumnado no universitario [Digital competences of non-university student]. RELATEC, 16(1), 7-20. DOI:10.17398/1695-288X.16.1.7

Coll, C. y Rodríguez-Illera, J. (2008). Alfabetización, nuevas alfabetizaciones y alfabetización digital: Las TIC en el currículum escolar. En C. Coll y C. Monereo (Eds.), Psicología de la educación virtual (pp. 325-347). Madrid: Morata.

De la Orden, A. (2011). Reflexiones en torno a las competencias como objeto de evaluación en el ámbito educativo. Revista Electrónica de Investigación Educativa, 13(2), 1-21.

De Pablos-Pons, J., Colás-Bravo, P. Conde-Jiménez, J. y Reyes-De Cózarla, S. (2017) Competencia digital de los estudiantes de educación no universitaria: variables predictivas. Bordón, 69, 169-185.

Dornaleteche, J.; Buitrago, A. y Moreno, L. (2015). Categorización, selección de ítems y aplicación del test de alfabetización digital online como indicador de la competencia mediática. Comunicar: Revista Científica de Comunicación y Educación, 22(44), 177185.

Dussel, I. (2009). Los nuevos alfabetismos en el siglo XXI: Desafíos para la escuela. Recuperado http://www.virtualeduca.info/Documentos/veBA09\%20_confDussel.pdf

Fain, M. (2011) Assessing Information Literacy Skills Development in First Year Students: A Multi-Year Study. The Journal of Academic Librarianship, 37(2), 109-119. http://dx.doi.org/10.1016/j.acalib.2011.02.002.

Ferrari, A. (2013). DIGCOMP: A Framework for Developing and Understanding Digital Competence in Europe. Sevilla: Joint Research Centre, Institute for Prospective Technological Studies. http://dx.doi.org/10.2788/52966

Ferrés, J., García, A., Aguaded, J. I., Fernández, J., Figueres, M., Blanes, M. y Zarandona, E. (2011). Competencia mediática. Investigación sobre el grado de competencia de la ciudadanía en España. Madrid: INTEF-Ministerio de Educación. Recuperado de http://ntic.educacion.es/w3/competencia_mediatica/competencia_mediatica.pdf

Fontdevila, P. A. (2012). Estudio de caso: Conectar Igualdad. Revista Iberoamericana de ciencia, tecnología y sociedad, 6(18), 179-181.

García, R.; Duarte, A. y Guerra, S. (2014). Propuesta de un instrumento de evaluación para medir el grado de competencia mediática en la etapa de la educación infantil. Pixel-Bit: Revista de medios y educación, 44, 81-96.

García-Umaña, A. (2017). Impacto social y educativo del comportamiento mediático digital contemporáneo: Nomofobia, causas y consecuencias. Dilemas contemporáneos, 5(1), 121. Recuperado de https://goo.gl/

García-Umaña, A. y Tirado-Morueta, R. (2018). Digital media behavior of school students: abusive use of the internet. Journal New Approaches in Educational Research, 7 (2), $152-159$.

García-Valcárcel, A. (2016). Las competencias digitales en el ámbito educativo. https://gredos.usal.es/jspui/handle/10366/130340

García-Valcárcel, A., Hernández, A., Mena Marcos, J.J., Iglesias, A., Casillas, S., Cabezas, M., González, L. M., Martín, M. y Basilotta, V. (2019a). Modelo de indicadores para evaluar la competencia digital de los estudiantes tomando como referencia el modelo DIGCOMP (INCODIES). https://gredos.usal.es/jspui/handle/10366/139409

Evaluación de las competencias digitales sobre seguridad de los estudiantes de Educación Básica, García-Valcárcel, A., Salvador, L., Casillas, S. y Basilotta, V.

Página 22 de 34 
García-Valcárcel, A., Hernández, A., Mena Marcos, J.J., Iglesias, A., Casillas, S., Cabezas, M., González, L. M., Martín, M. y Basilotta, V. (2019b). Prueba para evaluar la competencia digital de los estudiantes tomando como referencia el modelo DIGCOMP (ECODIES): área de seguridad. https://gredos.usal.es/handle/10366/139723

Gewerc, A. y Montero, M. (2015). Conocimiento profesional y competencia digital en la formación del profesorado. El caso del Grado de Maestro en Educación Primaria, Revista Latinoamericana de Tecnología Educativa, 14(1), 31-43. Recuperado de http://relatec.unex.es/article/view/1829/1191

González, J., Espuny, C., de Cid. M. J. y Gisbert, M. (2012). INCOTICESO. Cómo autoevaluar y diagnosticar la competencia digital en la Escuela 2.0. Revista de Investigación Educativa, 30(2), 287-302.

Gutiérrez, A. y Tyner, K. (2012). Alfabetización mediática en contextos múltiples. Comunicar, 19(38), 10-12.

He, T. y Li, S. (2019). A comparative study of digital informal learning: The effects of digital competence and technology expectancy, British Journal of Educational Technology, 0 (0), 1-15.

Ilomäki, L., Kantosalo, A., y Lakkala, M. (2011). What is digital competence? Brussels: European Schoolnet. Recuperado de http://linked.eun.org/web /guest/in-depth3.

INE (Instituto Nacional de Estadística) (2018). Encuesta sobre equipamiento y uso de tecnologías de información y comunicación en los hogares. Recuperado de https://www.ine.es/dyngs/INEbase/es/operacion.htm?c=Estadistica_C\&cid=125473617 $6741 \&$ menu=ultiDatos\&idp $=1254735976608$

Jenkins, H. (2009). Confronting the challenges of participatory culture: media education for the 21st century. Cambridge, MA: The MIT Press.

Katz, I. R. (2007). Testing information literacy in digital environments: ETS's iSkills assessment. Information technology and Libraries, 26(3), 3-12.

Kim, M., \& Choi, D. (2018). Development of youth digital citizenship scale and implication for educational setting. Journal of Educational Technology \& Society, 21(1), 155-171.

Lankshear, C. y Knobel, M. (2008). Digital Literacies: Concepts, Policies and Practices. New York: Peter Lang.

Livingstone, S., Haddon, L., Görzig, A. y Ólafsson, K. (2011). Risks and safety on the internet: the UK report. LSE, London: EU Kids Online.

López Pastor, V. M. (2009). Fundamentación teórica y revisión del estado de la cuestión. En V. M. López Pastor (coord.). Evaluación formativa y compartida en Educación Superior (pp. 45-64). Madrid: Narcea.

Martínez- Serrano, M.C. (2018) Diseño y validación de un cuestionario sobre la competencia digital del alumnado de educación primaria, Eduser, 10 (2), 1-15.

Mateo, J. y Martínez, F. (2008). Mediación y evaluación educativa. Madrid: La Muralla.

Muñiz, J. (1992). Teoría clásica de los test. Madrid: Pirámide.

Oberst, U., Wegmann, E., Stodt, B., Brand, M. y Chamarro, A. (2017). Negative consequences from heavy social networking in Adolescents: The mediating role of fear of missing out. Journal of Adolescence, 55, 51-60.

Odgerd, C. (2018). Smartphones are bad for some teens, not all. Nature, 555(7698), 432-580. doi:10.1038/d41586-018-02109-8

Evaluación de las competencias digitales sobre seguridad de los estudiantes de Educación Básica, García-Valcárcel, A., Salvador, L., Casillas, S. y Basilotta, V.

Página 23 de 34 
Rodríguez-Conde, M. J., Olmos, S. y Martínez, F. (2012). Propiedades métricas y estructura dimensional de la adaptación española de una escala de evaluación de competencia informacional autopercibida (IL-HUMASS). Revista de Investigación Educativa, 30 (2), 347-365.

Sánchez, P.; Muñoz, T. y Paredes, J. (2015). El trabajo en el aula y la competencia digital en el modelo 1 a 1 de la Comunidad de Madrid. Píxel-Bit. Revista de Medios y Educación, 47. Recuperado de http://acdc.sav.us.es/pixelbit/images/stories/p47/14.pdf

Sekret, I. V. y Kommers, P. A. M. (2014). Conceptual issuses of the digital competence development in the framework of the Council of the European Union. En M. Turčáni, M. Drlík, J. Kapusta y P. Švec (Ed.), DIVAI 2014 - Distance Learning in Applied Informatics. Conference Proceedings (s.p.). Nitra (Slovakia): Faculty of Natural Sciences, Department of Informatics.

Van Deursen, A. y Van Dijk, J. (2011). Internet skills and the digital divide. New media \& Society, 13(6), 893-911 DOI: 10.1177/1461444810386774.

Van Deursen, A. y Van Diepen, S. (2013) Information and strategic Internet skills of secondary students: A performance test. Computers \& Education 63, 218-226.

Van Dijk, J. y Van Deursen, A. (2014). Digital skills: unlocking the information society (First edition). New York, NY: Palgrave Macmillan.

Vekiri, I. (2010). Socioeconomic differences in elementary students' ICT beliefs and out-ofschool experiences. Computers \& Education, 54, 941-950.

Villa, A. y Poblete, M. (2011). Evaluación de competencias genéricas: Principios, oportunidades y limitaciones. Bordón, 63(1), 147-170.

Villegas Pérez, M., Mortis Losoya, S. V., García López, R. I. y del Hierro Parra, E. (2017). Uso de las TIC en estudiantes de quinto y sexto grado de educación primaria. Apertura, 9(1), 50-63.

Zhitomirsky-Geffet, M. y Blau, M. (2016). Cross-generational analysis of predictive factors of addictive behavior in smartphone usage. Computer in Human Behavior, 64(1), 682 693. doi:10.1016/j.chb.2016.07.061

Zhong, Z. (2011). From access to usage: The divide of self-reported digital skills among adolescents. Computers \& Education, 56, 736-746.

Anexo I. Prueba de evaluación de las competencias digitales de seguridad de los escolares (García-Valcárcel, Hernández, Mena , Iglesias, Casillas, Cabezas, Martín y Basilotta, 2019b)

Ítems de conocimiento y capacidad 
RED. Revista de Educación a Distancia. Núm. 61, Artíc. 05, 30-10-2019

DOI: http://dx.doi.org/10.6018/red/61/05

\section{1) PROTECCIÓN DE DISPOSITIVOS}

\begin{tabular}{|c|c|}
\hline CONOCIMIENTO & $\begin{array}{l}\text { 1. Cuando mi ordenador, tablet o móvil ha sido infectado por algún } \\
\text { virus debo: } \\
\text { a. Pagar un rescate por recuperar la información. } \\
\text { b. Pasar inmediatamente el antivirus (correcta). } \\
\text { c. Seguir trabajando normalmente como si no hubiera } \\
\text { pasado nada. }\end{array}$ \\
\hline CAPACIDAD & $\begin{array}{l}\text { 2. ¿Qué contraseña pondría para proteger mi ordenador, tablet o } \\
\text { móvil? } \\
\text { a. Mi nombre y fecha de nacimiento. } \\
\text { b. Mi número de DNI. } \\
\text { c. Mi dirección del domicilio. } \\
\text { d. Las iniciales de mi cantante favorito y del año que nació } \\
\text { (correcta). }\end{array}$ \\
\hline CAPACIDAD & $\begin{array}{l}\text { 3. Cuando utilizo el ordenador: } \\
\text { a. De vez en cuando abro el antivirus y examino el disco } \\
\text { duro (correcta). } \\
\text { b. Nunca examino con el antivirus el ordenador. } \\
\text { c. No uso antivirus porque nunca lo he necesitado. } \\
\text { d. Uso el antivirus sólo para revisar dispositivos externos } \\
\text { (ej. pen-drive....). }\end{array}$ \\
\hline CAPACIDAD & $\begin{array}{l}\text { 4. Si pongo una contraseña siempre sigo estas normas: } \\
\text { a. Que tenga muchos y variados caracteres (mayúsculas, } \\
\text { minúsculas, números, símbolos, etc.) (correcta). } \\
\text { b. Que sea una palabra corta para poderla recordar mejor. } \\
\text { c. Que solo tenga minúsculas. } \\
\text { d. Que tenga solamente letras. }\end{array}$ \\
\hline
\end{tabular}

En rojo se muestra las respuestas correctas

\section{2) PROTECCIÓN DE DATOS PERSONALES}

Evaluación de las competencias digitales sobre seguridad de los estudiantes de Educación Básica, García-Valcárcel, A., Salvador, L., Casillas, S. y Basilotta, V.

Página 25 de 34 


\begin{tabular}{|l|r|}
\hline CONOCIMIENTO & $\begin{array}{r}\text { Si publico fotos o datos sobre mi familia, como fotos de mi casa, } \\
\text { la profesión de mis padres, la calle donde vivo.... en Internet: }\end{array}$ \\
a. La información la controlo yo y la puedo borrar cuando \\
quiera. \\
b. Una vez que publico algo en Internet pierdo el control \\
sobre ello (correcta). \\
c. Sólo lo verán mis verdaderos amigos. \\
d. La información no afectará en ningún caso a mi futuro ni \\
al de mi familia.
\end{tabular}

Evaluación de las competencias digitales sobre seguridad de los estudiantes de Educación Básica, García-Valcárcel, A., Salvador, L., Casillas, S. y Basilotta, V.

Página 26 de 34 


\section{3) PROTECCIÓN DE LA SALUD}

\begin{tabular}{|c|c|}
\hline CONOCIMIENTO & $\begin{array}{l}\text { 9. Para evitar sufrir problemas de acoso a través de Internet: } \\
\text { a. No me fiaría de personas que no conozco y quieren } \\
\text { contactar conmigo (correcta). } \\
\text { b. No me comunico con nadie si no es presencialmente. } \\
\text { c. Considero que no voy a sufrir acoso a través de la Red } \\
\text { tal y como soy. } \\
\text { d. Utilizo una falsa personalidad en la Red. }\end{array}$ \\
\hline CAPACIDAD & $\begin{array}{l}\text { 10. Cuando me conecto con mis amigos para jugar: } \\
\text { a. Consigo mantener buenas relaciones con ellos aunque } \\
\text { vaya perdiendo en el juego (correcta). } \\
\text { b. Suelo enfadarme al poco tiempo y abandono el juego } \\
\text { formando otro grupo. } \\
\text { c. Me termino poniendo nervioso y después no duermo } \\
\text { bien. } \\
\text { d. Suelen ocurrir situaciones desagradables que nos } \\
\text { terminan enfrentando. }\end{array}$ \\
\hline CAPACIDAD & $\begin{array}{l}\text { 11. Cuando uso el ordenador, tablet, TV, consola de videojuegos... } \\
\text { en mi casa: } \\
\text { a. Me tumbo en el suelo. } \\
\text { b. Me siento correctamente en una silla, sofá, sillón, etc. } \\
\text { (correcta). } \\
\text { c. Me terminan doliendo la espalda, piernas o cuello. } \\
\text { d. No tengo una postura concreta y acabo cansado. }\end{array}$ \\
\hline CAPACIDAD & $\begin{array}{l}\text { 12. Cuando navego por Internet buscando una información que me } \\
\text { interesa: } \\
\text { a. Suelo tardar bastante porque encuentro páginas } \\
\text { divertidas con las que me entretengo. } \\
\text { b. Voy directamente a la información que necesito para } \\
\text { terminar cuanto antes (correcta). } \\
\text { c. Termino leyendo o viendo vídeos que no tienen nada que } \\
\text { ver con la información que buscaba. } \\
\text { d. Reviso normalmente muchas páginas pero no termino de } \\
\text { encontrar lo que quiero. }\end{array}$ \\
\hline
\end{tabular}

Evaluación de las competencias digitales sobre seguridad de los estudiantes de Educación Básica, García-Valcárcel, A., Salvador, L., Casillas, S. y Basilotta, V.

Página 27 de 34 


\section{4) PROTECCIÓN DEL ENTORNO}

\begin{tabular}{|c|c|}
\hline CONOCIMIENTO & $\begin{array}{l}\text { 13. Cambiar frecuentemente de ordenador, tablet, móvil, } \\
\text { videoconsola... } \\
\text { a. Tiene un impacto en el medio ambiente por generar } \\
\text { basura difícil de reciclar (correcta). } \\
\text { b. Es necesario cambiar frecuentemente los dispositivos } \\
\text { para poder utilizar las nuevas aplicaciones que van } \\
\text { saliendo. } \\
\text { c. No tiene ningún impacto negativo sobre el medio } \\
\text { ambiente. } \\
\text { d. No son cuestiones relacionadas con el medio ambiente. }\end{array}$ \\
\hline CONOCIMIENTO & $\begin{array}{l}\text { 14. La fabricación de móviles, tablet y otros dispositivos } \\
\text { electrónicos tiene un impacto medioambiental negativo que } \\
\text { afecta: } \\
\text { a. A todos los países y continentes por igual. } \\
\text { b. Solo a los países más desarrollados. } \\
\text { c. A los países menos desarrollados (correcta). } \\
\text { d. A ningún país ni continente. }\end{array}$ \\
\hline CAPACIDAD & $\begin{array}{l}\text { 15. Estoy realizando un trabajo en el ordenador y tengo que irme a } \\
\text { comer pero aún no lo he terminado: } \\
\text { a. Dejo el ordenador encendido porque en poco tiempo } \\
\text { volveré a terminar el trabajo. } \\
\text { b. Uso la opción "suspender" para ahorrar energía } \\
\text { (correcta). } \\
\text { c. Apago la pantalla y dejo encendido el ordenador. } \\
\text { d. Dejo encendido el ordenador sin plantearme nada más. }\end{array}$ \\
\hline CAPACIDAD & $\begin{array}{l}\text { 16. Si estoy jugando con un videojuego y me empiezo a sentir } \\
\text { nervioso y estresado por el ritmo que el juego me exige: } \\
\text { a. Dejo de jugar para evitar sentirme más nervioso } \\
\text { (correcta). } \\
\text { b. Sigo jugando porque un poco de estrés y nerviosismo } \\
\text { sirve para mejorar mi rendimiento en el juego. } \\
\text { c. Sigo jugando aunque mi rendimiento sea menor. } \\
\text { d. Nunca me plantearía dejar el juego por esa razón. }\end{array}$ \\
\hline
\end{tabular}

Evaluación de las competencias digitales sobre seguridad de los estudiantes de Educación Básica, García-Valcárcel, A., Salvador, L., Casillas, S. y Basilotta, V.

Página 28 de 34 
Anexo II. Modelo de indicadores para evaluar la competencia digital en el área de seguridad de los escolares. (García-Valcárcel, Hernández, Mena , Iglesias, Casillas, Cabezas, Martín y Basilotta, 2019a)

\section{Área: Seguridad}

Descripción general: Protección de información y datos personales, protección de la identidad digital, medidas de seguridad, uso responsable y seguro.

\section{Competencias:}

4.1 Protección de dispositivos.

4.2 Protección de datos personales e identidad digital.

4.3 Protección de la salud.

4.4 Protección del entorno.

\section{Protección de dispositivos}

Proteger los dispositivos propios y comprender los riesgos y amenazas en red, conocer medidas de protección y seguridad.

\section{Nivel básico}

Soy capaz de realizar acciones básicas para proteger mis dispositivos (por ejemplo, uso de antivirus, contraseñas, etc.).

1. Conocimiento sobre qué efectos pueden tener los virus en los dispositivos.

2. Conocimiento sobre cómo localizar y disponer de antivirus.

3. Capacidad para instalar antivirus en diferentes dispositivos (ordenador, tablet, móvil...).

4. Capacidad de formular contraseñas seguras.

5. Capacidad de identificar los sitios seguros donde interactuar en Internet (ej. jugar...).

6. Identificar portales seguros donde descargar información, software...

7. Actitud de precaución hacia los datos que se comparten en Internet. 
RED. Revista de Educación a Distancia. Núm. 61, Artíc. 05, 30-10-2019

DOI: http://dx.doi.org/10.6018/red/61/05

\section{Nivel intermedio}

Sé cómo proteger mis dispositivos digitales y actualizo mis estrategias de seguridad.

8. Conocimiento sobre distintos tipos de virus informáticos.

9. Conocimiento sobre distintos tipos de antivirus.

10. Capacidad de actualizar los antivirus y las contraseñas.

11. Capacidad de realizar diagnósticos del sistema y dispositivos para chequear virus...

12. Actitud de responsabilidad hacia la protección de los dispositivos (actualización de antivirus y contraseñas).

\section{Nivel avanzado}

Actualizo frecuentemente mis estrategias de seguridad y sé cómo actuar cuando el dispositivo está amenazado.

13. Conocimiento sobre cómo actuar en caso de tener un dispositivo afectado por un virus.

14. Conocimiento sobre cómo actuar en caso de otros problemas de seguridad (robo de cuenta, suplantación de identidad...).

15. Capacidad de gestionar las contraseñas utilizadas.

16. Capacidad para modificar las opciones de configuración del antivirus.

17. Uso de procedimientos para modificación (renovación) de contraseñas en las aplicaciones.

18. Actitud de actualización continua de las contraseñas como medida de seguridad.

\section{Protección de datos personales}

Entender los términos habituales de uso de los programas y servicios digitales, proteger activamente los datos personales, respetar la privacidad de los demás, protegerse a sí mismo de amenazas, fraudes y ciberacoso.

\section{Nivel básico}

Soy consciente de que en entornos en línea puedo compartir sólo ciertos tipos de información sobre mí mismo/a y sobre otros.

19. Conocimiento sobre la información personal que no se debe compartir en Internet.

20. Conocimiento de problemas que puede generar compartir información personal y de los demás.

21. Uso de procedimientos para proteger la identidad al instalar o utilizar aplicaciones.

Evaluación de las competencias digitales sobre seguridad de los estudiantes de Educación Básica, García-Valcárcel, A., Salvador, L., Casillas, S. y Basilotta, V.

Página 30 de 34 
22. Capacidad para discriminar la información que se debe o no publicar para proteger la identidad en las redes sociales.

23. Actitud de prudencia en cuestiones de privacidad hacia sí mismo y hacia los demás.

\section{Nivel intermedio}

Sé cómo proteger mi propia privacidad en línea y la de los demás. Entiendo de forma general las cuestiones relacionadas con la privacidad y tengo un conocimiento básico sobre cómo se recogen y utilizan mis datos.

24. Conocimiento sobre la importancia de la huella digital y el uso que pueden hacer los demás.

25. Conocimiento sobre el uso que pueden hacer terceras personas de su identidad digital

26. Capacidad para localizar información en Internet sobre sí mismo.

27. Uso de procedimientos para evitar la publicidad (bloquear ventanas pop-up...).

28. Uso de estrategias para proteger la identidad en las redes sociales.

29. Actitud respetuosa hacia la privacidad en línea, tanto la personal como la de otros.

\section{Nivel avanzado}

A menudo cambio la configuración de privacidad predeterminada de los servicios en línea para mejorar la protección de mi privacidad. Tengo un conocimiento amplio acerca de los problemas de privacidad y sé cómo se recogen y utilizan mis datos.

30. Conocimiento sobre el uso de datos personales por los proveedores de servicios online con fines comerciales.

31. Conocimiento de los beneficios de tener múltiples perfiles digitales para diferentes usos de la Red.

32. Capacidad de cuidar y mejorar la identidad digital.

33. Capacidad de modificar o eliminar información sobre sí mismo o sobre otros en el mundo digital.

34. Actitud crítica cuando muestra información en línea sobre sí mismo y los demás.

\section{Protección de la salud}

Evitar riesgos para la salud relacionados con el uso de la tecnología en cuanto a amenazas para la integridad física y el bienestar psicológico.

\section{Nivel básico}

Evaluación de las competencias digitales sobre seguridad de los estudiantes de Educación Básica, García-Valcárcel, A., Salvador, L., Casillas, S. y Basilotta, V.

Página 31 de 34 
Sé cómo evitar el ciberacoso.

Sé que la tecnología puede afectar a mi salud si se utiliza mal.

35. Conocimiento de las consecuencias del uso prolongado de las tecnologías (tiempo invertido en uso de Internet, problemas auditivos, oculares, posturales...).

36. Conocimiento de los aspectos adictivos de las tecnologías (efecto de las recompensas y premios obtenidos en forma de puntos, dinero...).

37. Conocimiento de las características y causas del ciberacoso.

38. Capacidad de controlar el tiempo en el uso de Internet.

39. Capacidad de establecer buenas relaciones personales y sociales entre pares a través de las redes sociales (tanto las generales como las específicas vinculadas al centro educativo).

40. Actitud de respeto y aceptación de las diferencias entre personas.

\section{Nivel intermedio}

Sé cómo protegerme a mí mismo y a otros del ciberacoso y entiendo los riesgos para la salud asociados al uso de tecnologías (desde los aspectos ergonómicos hasta la adicción a las tecnologías).

41. Conocimiento de pautas de protección frente al ciberacoso.

42. Conocimiento de los riesgos del uso de tecnologías digitales para la salud.

43. Conocimientos de pautas saludables (ej. ergonómicas, visuales, tiempos...) para el uso correcto de las tecnologías.

44. Capacidad para actuar de modo preventivo en relación al ciberacoso.

45. Capacidad para detectar conductas de ciberacoso entre compañeros.

46. Capacidad para prevenir la adicción a los diferentes dispositivos tecnológicos y las actividades realizadas a través de los mismos (ej. comunicación, juego...).

47. Capacidad para adoptar posturas ergonómicas (adecuadas).

48. Capacidad para actuar correctamente en caso de ciberacoso.

49. Actitud de prevención para evitar el ciberacoso.

50. Actitud de auto-control para evitar la adicción a las tecnologías.

\section{Nivel avanzado}

Soy consciente del uso correcto de las tecnologías para evitar problemas de salud. Sé cómo encontrar un buen equilibrio entre el mundo en línea y el mundo tradicional.

51. Capacidad para evitar los elementos distractores que originan la pérdida de tiempo en la actividad online.

52. Capacidad para adoptar medidas que permitan evitar las consecuencias nocivas del uso de las tecnologías.

53. Capacidad para adoptar conductas saludables en el uso de dispositivos tecnológicos (volumen adecuado de altavoces, tamaño adecuado del texto...). 
54. Capacidad para combinar alternativas de juego y comunicación presencial y online.

55. Actitud crítica ante el uso inadecuado de las tecnologías (tipo de información que se consulta, dispositivos, tiempos...).

56. Actitud de comprensión de las limitaciones impuestas por los padres/maestros en el uso de las tecnologías.

\section{Protección del entorno}

Tener en cuenta el impacto de las TIC sobre el medio ambiente.

\section{Nivel básico}

Tomo medidas básicas de ahorro energético.

57. Conocimiento de los problemas medioambientales relacionados con el uso de las tecnologías digitales.

58. Capacidad para tomar medidas de ahorro energético en el uso de los dispositivos tecnológicos (ej. suspender el sistema, apagar pantalla, desconexión del cargador...).

59. Actitud de respeto al medio ambiente desde el punto de vista tecnológico (ej. apagar el dispositivo cuando no se usa, alargar la vida de los dispositivos, reutilización...).

\section{Nivel intermedio}

Entiendo los aspectos positivos y negativos del uso de la tecnología sobre el medio ambiente.

60. Conocimiento sobre pros y contras de diferentes tecnologías para el medio ambiente

61. Conocimiento sobre los procesos de reciclaje de los dispositivos tecnológicos.

62. Conocimiento sobre el impacto que tiene la industria de fabricación de dispositivos tecnológicos en el medio ambiente.

63. Capacidad para optar por dispositivos tecnológicos con menos impacto en el medio ambiente (ej. que sean reciclables...).

64. Capacidad para utilizar el equipamiento digital de manera eficiente en cuanto a coste (uso de wifi donde es accesible...) y tiempo (limitando el tiempo de acceso).

65. Actitud positiva hacia el reciclaje (uso de puntos limpios...) y aprovechamiento de los dispositivos digitales.

66. Actitud crítica hacia el consumo injustificado de dispositivos digitales.

\section{Nivel avanzado}

Adopto una postura informada sobre el impacto de las tecnologías en la vida diaria, el consumo en línea y el medio ambiente. 
67. Conocimiento sobre el impacto medioambiental en diferentes lugares (ej. Continentes, países...) del uso actual de las tecnologías digitales.

68. Conocimiento sobre la forma de alargar la vida útil de los dispositivos digitales reciclando sus componentes.

69. Capacidad de utilizar servicios digitales sin depender completamente de ellos (saber buscar alternativas para realizar las tareas en caso de sufrir problemas tecnológicos).

70. Capacidad para utilizar las tecnologías de forma que las consecuencias sean positivas para las personas y el medio ambiente.

71. Conciencia de los beneficios y riesgos asociados con las tecnologías de la información.

72. Actitud de protección del medio ambiente por encima de las modas, consumismo... 